be useful to all who travel by sea. It begins by giving definitions indicating the sense in which the various technical expressions given aro used throughout. An 'earth', for example, is a connexion to the general mass of the hull of a steel ship, and detailed definitions are given of words like watertight, weatherproof, etc., so that the exact meaning of these words when they appear in marine contracts can be found.

For direct current, the standard voltages are 110 and 220 , but for small vessels, like tugs, trawlers, small yachts, fishing and similar small vessels, the standard voltages are 12,24 and 110 . The regulations are fairly stringent; for example, every seagoing ship in which electric power is used for essential services shall, except where other means are available for maintaining these services, bo provided with two or more generating sets of such combined output that in the event of one set being disabled the remaining generating plant shall be capable of supplying the essential services. Whero electric discharge lamps or luminous discharge tubes are used, lighting by one or more incandescent filament lamps shall be proviled as necessary to ensure safety in the event of the extinction of the discharge lamps. It must also be arranged that electric discharge lamps should operate satisfactorily with the ship inclined to the normal at any angle up to $15^{\circ}$ transversely and $10^{\circ}$ longitudinally, and with rolling up to $22 \frac{1}{2}^{\circ}$ with the vertical. We also learn that lightning conductors need not be fitted to steel ships having steel masts. Appendix 3 is very important, as the suppression of electrical interference with radio apparatus is clearly discussed. A list of devices and apparatus is given in regulation 413, which it is recommended should never be less than ten feet distant from any magnetic compass.

\section{Mining Electrical Engineers}

AT the first meeting this season of tho South Wales Branch of the Association of Mining Electrical Engineers, held at Cardiff last month, tho now branch president, Mr. D. J. Thomas, gave his inaugural address. He referred to the position of the colliery electrician, who is surrounded with regulations and restrictions, with equipment under his care on which many lives may depend, unless frequently inspected, and yet ho has little authority and practically no status. The equipment also with which he is provided has often passed its useful life, while much of the now equipment supplied is unsuitable for the class of work to which it is put. The apparatus has to withstand rough usage, and Mr. Thomas believes that there is insufficient appreciation on the manufacturers' part that there are conditions other than purely olectrical ones that have to be considered. The increasing amount of machine mining performed electrically and the wholesale electrification of surface and underground equipment make the modern colliery absolutely dependent upon electricity, and the mining electrical engineer holds $\mathfrak{a}$ position of very great responsibility. It is of vital importance that this should be recognized.

\section{British Museum (Natural History): Acquisitions}

A GIFT has been made to the Department of Mineralogy of a large polished slab of thodonite and pyrolusite, both manganese minerals, from Pencrebar, Callington, Cornwall, collected by the donor, Mr. Arthur Russell, president of the Mineralogical Society. A well-crystallized stilbite from Kalumpang, Ulu Selangar, has been presented by the Director of the Geological Survey of the Federated Malay States. This is the first zeolite specimen from that locality to bo added to the British Museum collections. - Three interesting specimens of Terra Sigillata have been presented by Mr. E. P. Bottley. Similar tablets of clay, formerly included in every pharmacopœia as an antidote for snake bites and poisons, were shaped and stamped from medicinal earth found in various localities, notably the Island of Lemnos, Greece, and Prussian Silesia. These three tablets are probably eighteenth century specimens and bear easily legible insignia and characters. They form a welcome addition to a very fine set belonging to the Sloane collection. Terra Sigillata clays and related materials, such as China clay, havo very high absorptive properties which render them of value in the treatment of dysentery and cholera.

\section{Negro Education in the United States}

American Negroes havo seldom played any notable part in education. A well-documented paper book, "Special Problems of Negro Education" (TVashington, D.C. : G.P.O. 25 cents), shows that coloured children suffer from an inequality. of chances compared with whites. The author, Prof. Wilkerson, has made several studies of the subject, and the results are gathered in this monograph. Negroes aro required by law to attend separate schools in eighteen States, from Alabama to West Virginia. Four fifths of them aro in the South and supply nearly one fourth of tho population. Is their education in separato schools adequate, and, if not, what ean be done to improve it ? These are the questions the author answers. The figures tabulated aro a little puzzling, but suggest on careful examination that during 1933-34 school attendance was considerably less among Negroes than whites. The Negro schools wero kept open on the whole for a shorter time, though States offer varying data. A racial difference of one school month becomes over a period of years a real handicap and leads to lower levels of scholastic achievement; pupils re. tarded in early grades are likely to drop out of school. Eminent authorities all agreo that they are quite as good in learning ability as whites. Transportation for education is important for rural districts, and here, too, they are handicapped, while they have fewer and worso-paid teachers. These disparities have been defended, but no sensible authority doubts that they should be eliminated. In Mississippi many of the coloured schools are housed in churches, old stores and shanties and lack decent comfort and educational materials. The story of higher education is similar, but it has to be noted that the Southern States in view are unable to finance public education at a satisfactory level. A much enlarged programmo 
of Federal aid is needed, and a recent decision of the United States Supreme Court recognizes the right of Negroes to "proper provision" of graduate and professional study. So the States must provide separate facilities for them, or admit them to their universities.

\section{Amendments to the Therapeutic Substances Act}

TrE Joint Committee which administers the Therapeutic Substances Act, 1925, has issued some amending regulations (Statutory Rules and Orders, 1939, No. 1395. H.M. Stationery Office. 2d. net). A new regulation requires that every holder of a licence to manufacture therapeutic substances, who engages in the culture or manipulation of pathogenic sporo-bearing micro-organisnus, shall provide soparate laboratories, utensils and apparatus required for the culture or manipulation of such micro-organisms. New regulations aro also imposed respecting the labelling, testing and standardization of tetanus toxoid and gas gangrene antitoxin.

\section{Earthquake in Turkey}

For the second time recently Turkey has been stricken by a disastrous earthquake. On September 22, the epicentre was near Smyrna (Nature, September 30 , p. 589). Now, on the morning of November 23 , an intense shock destroyed at least six villages in Anatolia. Eighteen people aro known to have been killed, but complete news is not yet available since telegraphic and other communications were interrupted by the earthquake.

\section{The Night Sky in December}

ON December 22 at $18 \mathrm{~h}$. the sun enters the sign Capricornus (the winter solstice). In the latitude of London, the night then lasts for $16 \frac{1}{4}$ hours. The moon is new on December 10 and full on December 16. Lunar conjunctions with the planets occur as follows : on December 9d. 10h. with Mercury; 13d. Ih. with Venus ; 18d. 10h. with Mars ; 19d. 8 h. with Jupiter ; and on 2ld. 8h. with Saturn. The geocentric distance between moon and Mercury at conjunction on December 9 is only $0 \cdot 2^{\circ}$. Mars, Jupiter and Saturn south at about $17 \frac{1}{2} \mathrm{~h} ., 18 \frac{1}{2} \mathrm{~h}$. and $20 \mathrm{~h}$. respectively in mid-December and are therefore well placed for observation in the ovening sky. Venus is also coming into visibility as an evening star and may be seen low in the south-west after sunset. Mercury is at greatest elongation $\left(21^{\circ} \mathrm{WV}.\right)$ on December 17 , and it may then bo seen low down in the south-east before sunrise. In the late evenings of this month, there is a fine array of stars between the eastern horizon and the meridian. The variable star, Algol ( $\beta$ Persei), souths at about $21 \frac{1}{2} \mathrm{~h}$. in mid-December. Its change of light is most easily noticeable about $1 \frac{1}{2}$ hours before and after the following epochs : December 4d. 4.8h.; 7d. I.7h.; 9d. 22.5h.; 12d. $19 \cdot 3 \mathrm{~h}$.; 15d. $16 \cdot 1 \mathrm{~h}$. ; 27 d. $3 \cdot 4 \mathrm{~h}$. and $30 \mathrm{~d} .0 \cdot 2 \mathrm{~h}$. To the east of Algol, spread over an area of about $2^{\circ}$ in diameter, is a cluster of about five hundred remote stellar systems. A member of another cluster in Gemini, for which a spectrogram was secured at the Mt. Wilson Observatory, shows a redward shift of the spectral lines equivalent to a speed of recession from the solar system of more than 14,000 miles per second and indicating $\Omega$ distance of 135 million light years. The Geminid meteors, with their greatest frequency about December 10-12, have a radiant point a few degrees preceding Castor. At midnight on December 31 , the brightest star, Sirius (mag. - $1 \cdot 6$ ), is $4 \frac{1}{2} \mathrm{~min}$. past the southern meridian.

\section{Announcements}

Ix view of the delay likely to be caused by postal difficulties in the present circumstances, writers of "Letters" submitted for publication in the correspondence columns are advised that, in general, proofs of communications will not be sent to authors outside Great Britain.

Dr. Germard DowaGk, who was recently awarded the Nobel Prize for Physiology and Medicine for 1939, has been elected an honorary member of the Pharmaceutical Association of the Hindu University of Benares.

Dr. JUan Jacobo Spangenberg has been nom. inated president of the National Department of Health of the Argentine Republic in succession to Dr. Miguel Sussieri, who has retired.

Tine King has been pleased to grant Dr. Herbert Chatley his authority to wear the insignia of the Order of the Brilliant Jade conferred upon him by the President of the National Government of the Republic of China, in recognition of valuable services rendered by him as engineer-in-chief of the Whangpoo Conservancy Board.

Prof. Douglas McCanduish, of the Department of Leather Industries of the University of Leeds, has been appointed honorary director, and Mr. W. R. Atkin honorary research assistant, of the Procter International Research Laboratory.

The Bradshaw Lecture of the Royal College of Surgeons of England will bo delivered at the College in Lincoln's Inn Fields by Sir James Walton, on December 14 at 3.30 p.m. The subject of the lecture will be "The Surgery of the Common Bile Duct".

A LEaGue against syphilis and other venereal diseases has been founded in Cuba under the auspices of the Cuban National Institute of Social Welfare.

Tine Central International Seismological Bureau has removed from Strasbourg to 9 , boulevard de la Pyramide, Clermont:Ferrand, France, from which address it will continue to function as hitherto.

Ax Elgar scholarship in naval architecture of the value of $£ 130$ per annum for three or four years is now being offered. Fntries close on January 15, 1940. Full particulars may be obtained from the Secretary of the Institution of Naval Architects, 10 Upper Belgrave Street, I.ondon, S.IW.I. 